\title{
Erratum to: Dimensions of Subjective Well-Being
}

\author{
Arie Kapteyn · Jinkook Lee $\cdot$ Caroline Tassot • \\ Hana Vonkova $\cdot$ Gema Zamarro
}

Accepted: 19 September 2014/Published online: 26 September 2014

(C) Springer Science+Business Media Dordrecht 2014

\section{Erratum to: Soc Indic Res \\ DOI 10.1007/s11205-014-0753-0}

In the Acknowledgments of the article a name was omitted.

The Acknowledgement should read:

We thank Richard Easterlin, Arthur Stone, Erik Meijer and two anonymous referees for very helpful comments.

The online version of the original article can be found under doi:10.1007/s11205-014-0753-0.

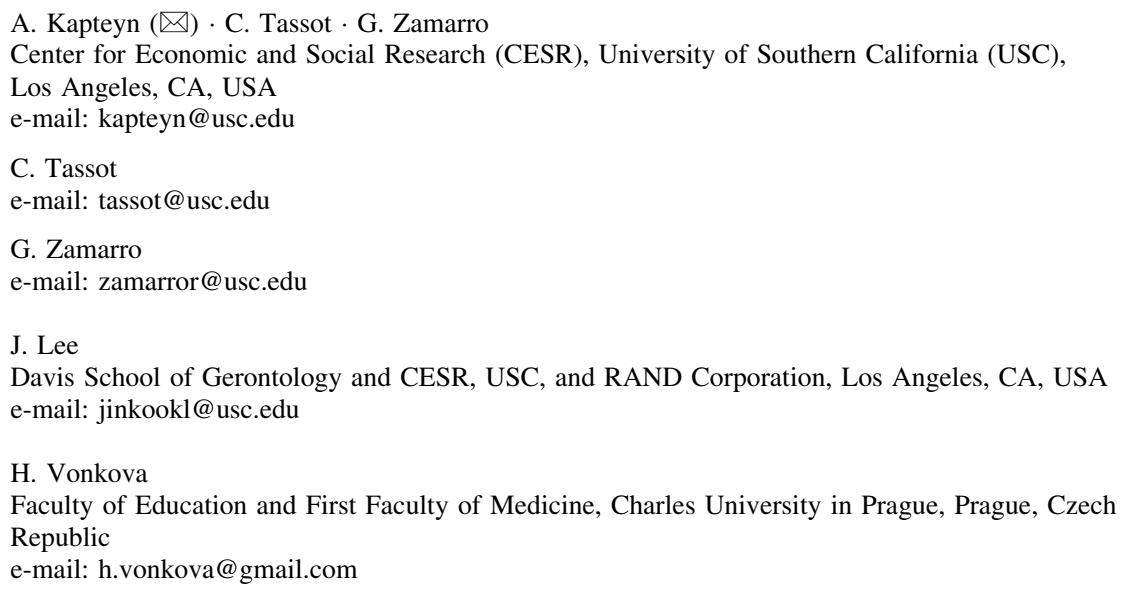

